\title{
The costs of COVID-19 and the cost-effectiveness of testing
}

\author{
Beatriz González López-Valcárcel and Laura Vallejo-Torres \\ Departamento de Métodos Cuantitativos en Economía y Gestión, \\ Universidad de Las Palmas de Gran Canaria, Las Palmas de Gran Canaria, Spain
}

\begin{abstract}
Purpose - This paper aims to provide an estimation of the costs of the coronavirus (COVID-19) pandemic with a special focus on Spain. Costs include macroeconomic costs of foregone gross domestic product (GDP) attributable to the pandemic and the direct and indirect costs of prevention, treatment and lost productivity. This study also analyzes the cost-effectiveness of the test-tracking-quarantine (TTQ) strategy in Spain.

Design/methodology/approach - The macroeconomic costs of foregone GDP attributable to the pandemic are estimated for different countries and areas by comparing the present GDP forecasts for 2020 and 2021 with counterfactuals estimated before the COVID-19 crisis aftermath. The total cost of the COVID-19 for Spain in 2020 was obtained using the cost of illness approach with a bottom-up process. A costeffectiveness analysis of the TTQ strategy in Spain is based on the estimation of the total costs of TTQ and the health gains and avoided health-care costs associated with the TTQ strategy. A sensitivity analysis explores the consequences of uncertainty in key parameters.
\end{abstract}

Findings - The GDP cost of the COVID-19 is by far larger than all the other components of the cost. The global cost of the Covid-19 crisis in 2020-2021 is estimated at 14\% of 2019 GDP (around $12,206 \mathrm{~mm} \$$ ). In the specific case of Spain, it amounts to $24 \%$ of the 2019 GDP; which is $397.3 \mathrm{~m} €$. Spain is and will be by far the European country most economically affected by the pandemic. In Spain 2020, the GDP cost accounts for $94.7 \%$ of the total cost of the COVID-19 and health-care direct costs are only $2.14 \%$. TTQ is a dominant strategy in Spain. For each euro spent on it, 7 euros will be recovered only in terms of saved health-care resources.

Research limitations/implications - Given the large degree of uncertainty and the fast-evolving nature of the epidemic, a number of assumptions are required to arrive at the estimates provided in this study. The results were found to be robust to the assumptions applied.

Practical implications - TTQ is a key strategy for the contention of the epidemy and it is justified from the economic perspective.

Originality/value - This is the first estimation of the cost of the COVID-19 and the cost-effectiveness of the TTQ strategy for Spain.

Keywords Cost-effectiveness, COVID-19, Burden of disease, Cost of disease, COVID testing strategy

Paper type Research paper

(C) Beatriz González López-Valcárcel and Laura Vallejo-Torres. Published in Applied Economic Analysis. Published by Emerald Publishing Limited. This article is published under the Creative Commons Attribution (CC BY 4.0) licence. Anyone may reproduce, distribute, translate and create derivative works of this article (for both commercial and non-commercial purposes), subject to full attribution to the original publication and authors. The full terms of this licence maybe seen at http:// creativecommons.org/licences/by/4.0/legalcode

This article was funded by the Research Project COVID-19 of the University of Las Palmas de Gran Canaria (ULPGC). Reference: COVID 19-01. Title: Socioeconomic impact of the COVID-19 in Spain with special attention to the Canary Islands: diagnosis and proposals for recovery. 
AEA

29,85

\section{Introduction and conceptual framework}

Studies of the cost of illness, which approximate the burden of disease, are a classic in health economics (Akobundu et al, 2006). They account for direct health-care costs for a region or country, indirect costs of lost productivity due to premature mortality and morbidity and costs of informal care attributable to a particular disease or group of diseases. For example, for Spain and other European countries, the costs of cardiovascular diseases (Leal et al., 2006), mental diseases (Oliva-Moreno et al., 2009) and cancer (Luengo-Fernandez et al., 2013) have been calculated using this methodology. These studies are based on the burden of disease (mortality, quality-adjusted life years (QALYs) lost, disability-adjusted life years (DALYs) lost) attributable to different risk factors and diseases. There is a global project called Global Burden of Disease, whose results are regularly published by the Lancet (Vos et al., 2020) [1].

In the case of the coronavirus (COVID-19), as in other communicable diseases that generate strong externalities, to approximate the cost of the disease, it is necessary to include the economic cost of the drop in gross domestic product (GDP) as a result of the infection itself and the measures taken to deal with it. For example, the macroeconomic costs of AIDS in African countries are estimated at around an annual 1\% loss of GDP and the long-run economic costs are expected to be much higher (Bell et al., 2003). GDP falls through three mechanisms (Carlsson-Szlezak et al., 2020):

- the reduction of consumption and increase in savings due to the expectations of families;

- the loss of net wealth linked to the downwards evolution of the financial markets, which ends up being transferred to the real economy; and

- the disruption of supply, supply chains, etc., that have a direct impact on employment and productivity.

In a broad sense, the costs of COVID-19 include the drop in GDP, as well as the direct costs, both health and non-health, of prevention and treatment. Direct health-care costs include individual protection equipment, contact tracers, tests and vaccines. They also include the treatment costs of the disease and its long-term physical and mental sequelae. The direct costs that fall outside the health-care sector include a variety of components such as quarantine facilities, the cost of organization changes in schools and nursing homes and the special measures to protect any kind of facilities and buildings from COVID-19 infections. There is also an opportunity cost of idle health-care resources that remain unused during the pandemic, should the epidemic worsen, reserved for potential COVID-19. Indirect costs account for the costs of morbidity, mortality and quarantines in terms of losses of productivity. Some studies include as well the so-called "value of a statistical life" which proxies the economic valuation of life for statistical purposes.

For the USA, the cost of the COVID-19 has been estimated at about $\$ 13 \mathrm{tn}$ ( $90 \%$ of the country's annual GDP) and about half of that figure corresponds to the 10-year decline in GDP attributable to the pandemic (Cutler and Summers, 2020). Mulligan (2020) estimates a cost, also for the US, of \$7bn per year in terms of welfare loss. In another study for the US, Bethune (2020) estimates that the marginal cost of an infection, in terms of the fall in economic activity, is $\$ 286,000$.

In this study, we provide an estimation of the cost of the COVID-19 in Spain, including macroeconomic costs of foregone GDP and direct and indirect costs of prevention, treatment and health losses. In addition, we analyzed the cost-effectiveness of the test-trackingquarantine (TTQ) strategy conducted in Spain. This is the first study providing estimates on both of the above issues for the Spanish context. The paper is structured as follows. Section 2 describes methodological issues related to cost-of-illness studies and particularly 
with respect to the quantification of the GDP fall attributable to the disease. In Section 3, estimates of the macroeconomic costs of COVID-19 around the globe and in selected countries are presented, alongside the first estimation of the total costs of COVID-19 in Spain. The cost-effectiveness of the TTQ strategy conducted in Spain is presented in Section 4. Section 5 summarizes the findings of this study and provides some concluding remarks.

\section{Methodological issues}

Some methodological issues deserve attention in the cost of disease studies (Byford et al., 2000). As for the perspective of the analysis, generally, it is adopted that of the society, which includes the social costs in addition to the private ones. This distinction is important in the case of diseases with externalities such as the COVID-19, whose social costs are much higher than the private ones. Generally, only tangible costs are valued, that is, those associated with goods and services that can be marketed or valued by the market, even if they do not pass through the market such as informal care (which for COVID-19 might not be very relevant). Intangible costs, related to the suffering produced by the disease, are not incorporated. As for the estimates of attributable mortality, they must be adjusted for confounding factors and take into account the existence of comorbidities. For example, a patient with advanced cancer who gets COVID-19 on the hospital's palliative care floor will feature in the official mortality statistics for COVID-19.

To estimate the health costs of the disease there are two approaches, the first operates top-down, the second bottom-up. The latter is the most appropriate approach for COVID-19. It consists of aggregating the patient's micro-data costs of prevention, treatment and followup. Costs of community programs as contact tracing are also added. The time horizon varies according to the uses to which the study is to serve.

\subsection{Methodology for estimating the cost attributable to the COVID-19 in terms of the fall in gross domestic product}

To estimate the macroeconomic cost attributable to the COVID-19, in terms of the fall in a country's GDP, we compare the observed or predicted GDP with the counterfactual estimated under the assumption that the epidemic would not have existed. The time horizon should not be long to avoid alphabetical-like speculation on recovery patterns (in V, in W...). Given that effective vaccines are likely to be available during 2021, we use a two-year horizon (2020 and 2021).

Macroeconomic forecasts are very uncertain and depend on assumptions on the availability of effective vaccines, interpersonal behavior mobility and adherence to restrictions to economic activity. For that reason, forecasts are regularly updated. Short term forecasts are more reliable. For instance, even though the second wave of the pandemics is beating Europe, in the second wave "lockdowns will be less stringent -schools, factories and construction will remain openwhile the initial disruption associated with switching to remote working is likely to be less than six months ago" (May, 2020). Other than that, predictions about GDP, current and counterfactual, must come from the same source. We used the figures provided by the International Monetary Fund (IMF) in the World Economic Outlook of October 2020 (IMF, 2020c) with the counterfactual pre-COVID-19 predictions of January 2020 (IMF, 2020a).

For a given country, the cost in terms of GDP of the epidemic can be conceptually separated into three causes:

(1) exogenous to the country, according to the global evolution of the pandemic and specifically in the countries that are economically most interconnected with the one being analyzed; for example, a high incidence in the major contributing countries to Spain's tourism would reduce the entry of tourists, as a result of travel restrictions and due to peoples' safety concerns about traveling abroad; 
AEA

29,85

(2) causes related to the evolution of the epidemic out of control by governments, that is, if the optimal policy of the "social planner" were implemented, given the knowledge about the disease and the impact of interventions; and

(3) fall in GDP caused by "avoidable" restrictions on economic activity, that is, beyond the optimal ones. There is recent economic literature on the optimal restrictions by a social planner -for a review, see (Brodeur et al., 2020).

Although conceptually the three causes are clear and well defined, in practice it is impossible to separate them because there is enormous uncertainty about the epidemic and economic impact of restrictions on human interaction, mobility and economic activity; in fact, there is a heated debate between scientists positioned in "opposing sides" of the liberal - interventionist axis (Kulldorff et al., 2020; Alwan et al., 2020). Therefore, we will calculate the total cost of the impact on GDP without breaking it down by the three causes listed above.

There is huge heterogeneity among countries in anti-COVID-19 measures and interventions [2], both in health protection and in the protection of the economic problems of families and businesses arising from the pandemic; there is also enormous variety in the application of restrictions (Cylus and van Ginneken, 2020). The COVID-19 health system response monitor (HSRM) [3], a platform created by the WHO Regional Office for Europe, the European Commission and the European Observatory on Health Systems and Policies, tracks the responses of the countries to the COVID crisis.

This heterogeneity can also be seen in the fiscal effort and the discretionary fiscal response to the COVID-19 crisis. Some countries provided large liquidity support, others large amounts of additional spending and tax exemptions. The spending in Spain is small compared to other countries, $3.5 \%$ of the GDP in public spending and foregone revenues. Liquidity support amounts to $14 \%$ of the GDP and it is higher than in other countries but small compared to Italy, Germany or Japan (IMF, 2020b).

\section{What do we know so far about the macroeconomic costs of the COVID-19? International perspective}

This is the worst crisis since the [. . . Great Depression at the end of the 1920s, to the extent that "The pandemic will reverse the progress made since the 1990s in reducing global poverty and will increase inequality" (IMF, 2020c). Table 1 contains estimates of the macroeconomic global costs of the COVID-19 for 2020 and 2021 and also for the Eurozone and a selection of developed countries, including the USA, UK, Germany, France, Spain, Japan, Italy and Canada. The values are reported in thousand million USA dollars ( $\mathrm{mm} \$$ ).

The global cost of the COVID-19 crisis is estimated at 14\% of 2019 GDP (around $12,206 \mathrm{~mm} \$$ ). In the specific case of Spain, it amounts to $24 \%$ of the 2019 GDP (around $336.7 \mathrm{~mm} \$, 200.8$ of them in 2020 and 135.9 in 2021 [4]). Furthermore, Spain will be, by far, the European economy most affected by the pandemic.

\subsection{The specific case of Spain}

There are no public data yet to approximate the total costs of the COVID-19 pandemic in Spain according to the cost-of-illness methodology described in Section 2.1. It is worth mentioning, however, that the opportunity costs of underusing resources such as keeping hospital beds or surgical rooms free for possible COVID-19 patients are substantial. For example, Abásolo Alessón et al. (2020) estimated the extra costs attributable to COVID-19 in the Canary Islands for the first half of 2020. Never have public hospitals been so empty as in April 2020, with occupancy rates below 60\%. COVID-19 caused an extra direct health-care cost of almost $11 \%$ of the total public health expenditure in the archipelago and has 


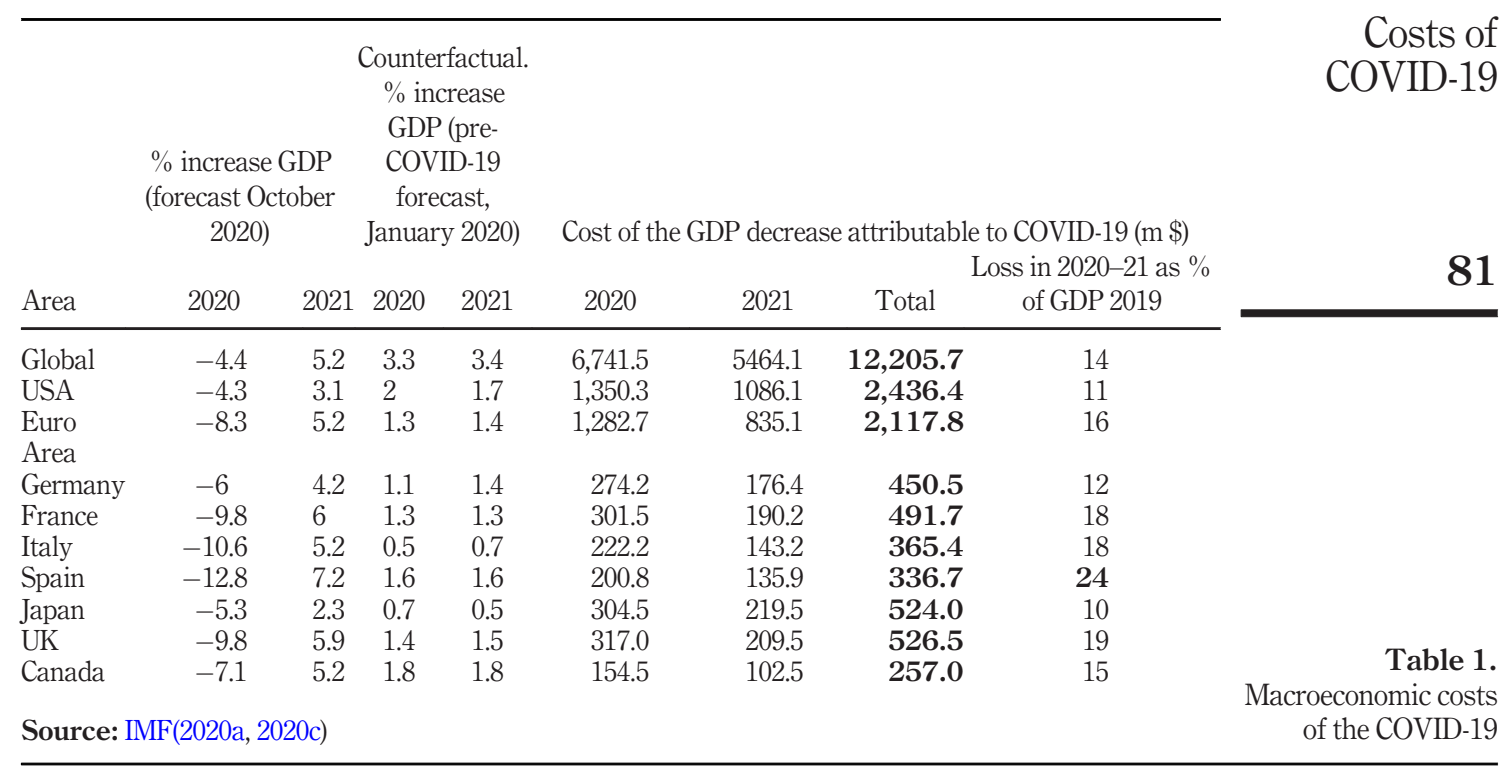

postponed health-care expenditures for patients with other diseases not treated during the first wave of the pandemic, in addition to the costs associated with health losses and productivity of these individuals.

To advance in the knowledge of the costs of COVID-19 in Spain, this paper contributes a "back of the envelope" quantification to assess the order of magnitude of health costs compared to economic costs and to approximate the return of public spending on prevention.

Until the 8th of November 2020, 175,477 COVID-19 patients had been hospitalized in Spain, of which 14,734 correspond to intensive care unit (ICU) stays. If the rate of the week from November the 2nd to November the 8th was to remain constant for the remainder of the year, by the end of 2020 almost 200,000 patients would have been admitted to a hospital ward and about 18,000 to an ICU. The average cost of a COVID-19 patient treated in a hospital ward is about 8,500 €assuming an average stay of 11.5 days in the first wave and 7 days in the second and the average daily cost estimated by Osakidetza (2019). The average cost of a COVID-19 patient in an ICU is about 33,400 €-assuming, in this case, an average stay of 22 days for those who do not die and 10 days for those who die and the average daily cost also estimated by Osakidetza (2019). Therefore, in 2020 the direct cost of hospitalization in Spain might be in the order of magnitude of $2,300 \mathrm{~m} €$. However, direct costs of COVID-19 include not only hospitalizations. To proxy total direct costs, we used the amounts transferred from the central government to the Ministry of Health and the Autonomous Communities to meet the costs of prevention and treatment of COVID-19. They amount a total of 5,350m $€$, including $1,400 \mathrm{~m} €$ to the Ministry of Health for centralized purchases; $2,900 \mathrm{~m} €$ to the Autonomous Communities to meet extraordinary health expenses and 1,050m € for other health expenses, including research. Assuming that this figure approximates the direct costs of COVID-19, these would be equivalent to one month of spending on the temporary labor force adjustment plan (ERTES [5]) and the health-care costs of COVID-19 would barely represent $2.2 \%$ of the costs in terms of GDP loss in 2020 of Table 1.

On the other hand, until November $11^{\text {th }}, 2020,40,769$ people have died from COVID-19 in Spain according to official national statistics. The excess of mortality estimated by the 
AEA 29,85

ISCIII monitoring system (see MoMo reports), is much higher reaching 63,345 deaths [6]; this figure might include those who died from other causes that have been neglected by the health system during the COVID-19 crisis - the so-called invisible patients -, as well as those not accounted for in official statistics because they were not tested for COVID-19. Assuming a stationary rate for the remainder of 2020 of 160 daily deaths (in the 14 days prior to the 11th November there was 210), the final figure of "official" deaths recorded in 2020 is estimated at 48,609. Given the age distribution of the deceased (since May 11th, when the system switched to an individualized data system, $66 \%$ of the deceased are over 80 years old and 26\% between 60 and 80) and the life expectancy in Spain (84 years), we estimate an average of five years of life lost due to premature mortality per fatality. This represents near 244,000 years of life lost in total in 2020. Using data from the National Health Survey for Spain [7] in 2011-2012, we estimate that the average Quality-of-Life (QoL) weight among individuals over 80 years of age in Spain is 0.618 . Using a 3\% discount rate, the number of Quality-Adjusted Life Years (QALYs) lost due to premature mortality is estimated at 141,703 .

The percentage of COVID-19 patients that will suffer long-term health consequences is unknown, but accumulating evidence demonstrates morbidity beyond acute infection (Datta et al., 2020). The most common lasting consequences are related to respiratory complications. A number of studies have found this to be the case in $39 \%, 44 \%$ and $47 \%$ of COVID-19 patients (Mo et al., 2020; Wei et al., 2020; Yu et al., 2020). Neurological, cardiovascular, musculoskeletal and skin-related complications have also been reported, alongside persistent mental health problems (Ministerio de Sanidad, 2020). We assume a third of COVID-19 cases that require hospitalization will suffer a long-term health complication and estimate the associated QALYs lost due to long-term morbidity. To measure the disutility associated with a potential COVID-19 persisting complication we compare the QoL weight of individuals 65 years of age and over (as this is the mean age of cases requiring hospitalization) with and without a long-term health impairment. These were found in the 2011-2012 Health Survey for Spain to be 0.723 and 0.911 , respectively. Therefore, we approximate the disutility of a long-term complication at -0.188 . Taking the remaining life expectancy of these individuals and a 3\% discount rate, the number of QALYs lost per patient with a long-term complication is 2.8 QALYs, amounting to 170,510 QALYs lost due to morbidity when considering the total number of projected cases with a long-term complication expected in 2020 based on the above assumptions (estimated in 60,896).

Productivity costs associated with mortality and/or long-term morbidity are not considered as the mean age among the COVID-19 patients who died or had moderate to severe symptoms is close to or above retirement age in Spain as shown above. Moreover, to assign a monetary value to the mortality and morbidity-related health losses attributed to COVID-19, we depart from the methodology used by Cutler and others (Cutler and Summers, 2020) of applying the Value of a Statistical Life (VSL). The reason is the age profile of COVID-19 fatalities and severe cases in Spain and the controversy regarding the appropriate VSL over the life cycle (Aldy and Viscusi, 2007; Herrera-Araujo and Rochaix, 2020). Instead, we apply a monetary value of 25,000 $€ /$ QALY (Vallejo-Torres et al., 2018; Vallejo-Torres et al., 2020) to the estimated QALYs lost attributed to COVID-19, which already accounts for the extent of the remaining life expectancy and the QoL of the relevant individuals. The overall monetary value due to health losses is estimated at 7,805m $€$, which corresponds to $3.1 \%$ of the overall total cost of the economic crisis for Spain in 2020 attributable to COVID-19 (Table 2). The cost figure associated to lost GDP due to COVID-19 in Table 2 corresponds to the value estimated for Spain in 2020 presented in Table 1 but expressed in million $€$. 


\section{The cost-effectiveness of test, tracking and quarantine strategy}

Economic analyzes that have evaluated COVID-19 testing strategies conclude that their costs are largely offset by the health effects and/or the macroeconomic and fiscal benefits associated with wide-scale testing. Cutler and Summers (2020) estimated the economic returns of testing and tracing to be approximately 30 times the associated cost in the USA. In their analysis, economic returns were measured by the monetized value of lives saved and monetized avoidable long-term morbidity using an estimated VSL of $7 \mathrm{~m}$ dollars. Atkeson et al. (2020) estimated the benefit-to-cost ratio of COVID-19 screening testing programs to be in the range of 2 to 15. Contrary to Cutler and Summers (2020), economic returns were measured by the impact on GDP and on federal tax revenue resulting from the reduced number of COVID-19 cases, excluding the monetized value of lives saved.

These macroeconomic cost-benefit analyzes offer a clear picture of the extensive health effects and externalities in all sectors of the economy of the COVID-19 pandemic and emphasize the value of spread-containment interventions. However, these studies depart from the conventional framework of the economic evaluation of health interventions. In this section, we aim to provide an approximation of the cost-effectiveness of the TTQ strategy in Spain following a similar approach to that used in standard cost-effectiveness analysis used in an economic evaluation of health-care technologies (Drummond et al., 2005). To do so, we estimate the total costs and health gains and associated avoided health-care costs, of a TTQ strategy.

Our application is for Spain. We consider a selective TTQ strategy, which undertakes 4 PCR tests per thousand people daily [8] targeted to high-risk individuals, including persons with symptoms, contacts of identified cases, health workers, individuals living in retirement or nursing homes or in local areas with high prevalence, etc. The strategy also assumes a contact tracing capacity of one trained contact tracer per 5,000 inhabitants. The daily cost of such a strategy is summarized in Table 3 and amounts to over $8.7 \mathrm{~m} €$. Table 3 also reports the effect estimates and the cost-effectiveness analysis for the base case analysis.

The effectiveness of the strategy is measured by the number of avoided cases, which depends on a series of assumptions regarding:

- the positive testing rate;

- the number and the positive testing rate among close contacts;

- the potential for transmission at the time of detection;

- the adherence rate to quarantine; and

- the basic reproductive number (R0).

The values of these parameters and their sources taken in the base case analysis are summarized in Table 4, which also provides a sensitivity analysis to changes in these and other parameters. In addition, given the dynamic nature of the spread of the disease, the estimated number of cases avoided will ultimately lead to even fewer cases. In the base case analysis, we consider the number of cases avoided from the second week of November until the end of the year, i.e. three fortnights and thus we consider that each avoided case will prevent a total number of cases equal

\begin{tabular}{lcc} 
Cost component & Cost in 2020 (million $€)$ & $(\%)$ \\
\hline Direct health and non-health-care costs & 5,350 & 2.1 \\
Cost due to premature mortality and long-term morbidity consequences & 7,805 & 3.1 \\
Lost GPD due to COVID-19 outbreak and outbreak responses & 236,914 & 94.8 \\
Total & 250,069 & 100
\end{tabular}

Table 2.

Estimate of the total cost of the COVID-19 crisis for Spain in 
AEA
29,85

84

Table 3.

Economic and health consequences of the TTQ strategy in Spain

Estimate
TTQ strategy daily costs
Tests (unit cost per test)
Tracers (unit cost per day)

Health consequences prevented daily

COVID-19 total cases

COVID-19 cases treated at home

Hospitalizations

ICU stays

Cases suffering long-term morbidity

Deaths

QALY gains

QALY gain from avoided morbidity

QALY gain from avoided mortality

Total monetary costs

Total monetary savings

Incremental costs

Incremental QALYs

$\begin{array}{rrr}53,286 & & \\ 48,615 & 280 € & 13,612,174 € \\ 2,931 & 8,500 € & 24,911,191 € \\ 213 & 33,400 € & 7,118,703 € \\ 1,048 & 14,754 € & 15,461,009 € \\ 480 & & \end{array}$

2,908

1,398

Total costs

$8,716,758 €$

$61,103,076 €$

$-52,386,318 €$

4,306

Cost per QALY gained

Benefit-to-cost ratio (excluding health and morbidity)

Benefit-to-cost ratio (including health and morbidity)

Dominating

to 3 times the value of $\mathrm{R} 0$ (e.g. at an $\mathrm{R} 0=1$, each avoided case will prevent 3 extra cases within a month and a half).

The rates for hospitalization (5.5\%), ICU stays $(0.4 \%)$ and mortality $(0.9 \%)$ associated with COVID-19 cases are taken from the Ministry of Health data from May, 11th, 2020 to November 11th [9]; they, therefore, reflect the current situation excluding the significantly higher rates seen during the first wave of the pandemic in Spain. As in Section 3.1, we assume a third of COVID-19 cases that require hospitalization will suffer from a long-term health complication and we vary this in the sensitivity analysis. Health-care costs avoided due to fewer hospitalizations and ICU stays are estimated using the same unit costs as in Section 3.1. Health-care costs associated with long-term consequences are estimated considering an annual incremental cost of $1,000 €$ for the remaining life expectancy of patients suffering long-term complications, discounted at a $3 \%$ rate. This is similar to the incremental cost observed in the Basque Country for individuals with none or one chronic condition compared to individuals with one of two chronic conditions, respectively (Osakidetza, 2009). For COVID-19 cases not requiring hospitalization, we assume the costs of 10 phone contacts with the Primary Care doctor at a unit cost of $28 €$ [10] each.

Our results show that, for every single day of testing, the estimated number of cases avoided from November 15th until the end of December 2020 is 53,286 in the base case analysis (Table 3). This leads to 2,931 fewer hospitalizations, 213 fewer individuals requiring intensive care unit (ICU) stays, 1,048 avoided cases suffering from long-term morbidity and 480 fewer deaths. Health-care costs saved from averting these cases amount to $61.1 \mathrm{~m} €$.

We follow the same approach as in the previous section to measure the QALY gains associated with averted deaths and averted long-term morbidity cases associated with the TTQ strategy. This yields a total of 1,398 QALYs gained from avoided mortality and 2,908 QALYs gained from averted cases with long-term morbidity, i.e. 4,306 QALYs daily in total. 


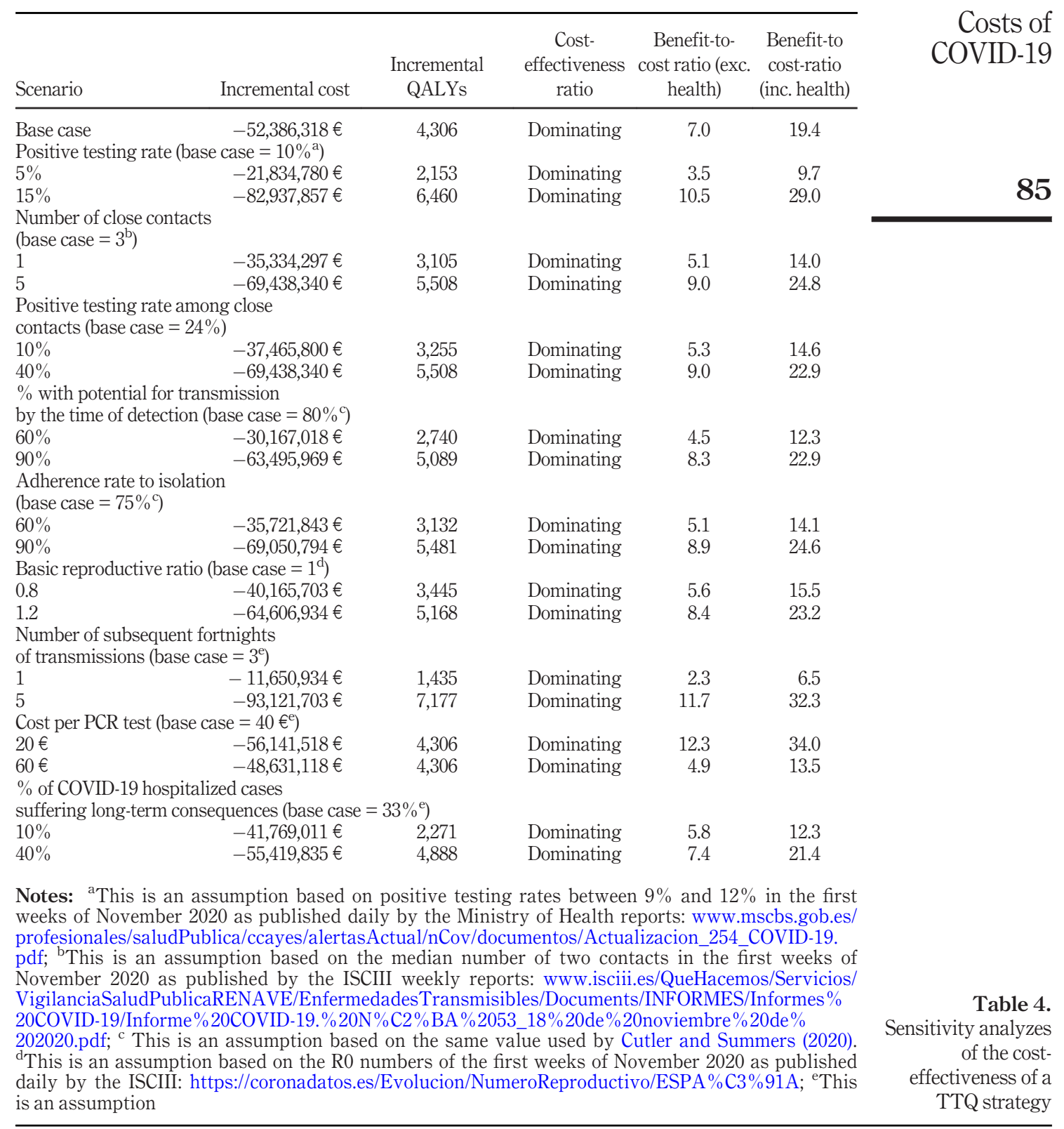


AEA 29,85
Table 3 presents the incremental cost of the TTQ strategy considering testing and tracing and avoided health-care costs, which are estimated at a saving of $52.4 \mathrm{~m} €$ per day. The TTQ is a dominating strategy; in simpler words, it leads to lower overall costs and better health outcomes. The benefit-to-cost ratio is 7.0 when only avoided health-care costs are considered on the benefit side and 19.4 when health and morbidity are monetized at a 25,000 €/QALY value and included as a benefit of the program.

Table 4 shows the cost-effectiveness results and benefit-to-cost ratios when the values of the parameters used in our estimations are varied. The results are robust to the assumptions applied. In every scenario considered, the TTQ strategy is found to be dominating (associated with lower costs and better health outcomes). The benefit-to-cost ratio excluding health and morbidity effects ranges from 2.3 to 12.3 , while it is in the range of 6.5 to 34.0 when monetized health gains are included.

Our estimates emphasize that the TTQ strategy as implemented in Spain at the end of 2020 is a highly cost-effective use of resources. This is so even when a narrower health-care system perspective, which only includes prevented health-care costs due to avoidable causes, is taken. If other broader avoidable costs such as non-health-care direct costs or indirect costs, including GDP effect, were taken into account the costeffectiveness of the TTQ strategy would be even much more favorable.

\section{Summary and conclusions}

Globally, the macroeconomic cost of the Covid-19 in terms of lost GDP in two years, 2020 and 2021, is $14 \%$. For Europe, it is even higher, $16 \%$ for the Eurozone, $19 \%$ for the UK. Within Europe, Spain is and probably will be, the country hardest hit by the crisis, with a macroeconomic cost attributable to the Covid-19 accumulated in December 2021 equivalent to $24 \%$ of GDP in 2019. Compared to such an order of magnitude, the direct health cost is only a small part of the total cost attributable to COVID-19. In this article, we have applied the methodology of the cost of the disease to the COVID-19 for Spain. The purpose was to approximate the importance of the different components of the cost.

Moreover, once the direct and indirect health and non-health costs of COVID-19 have been calculated, we have made a cost-effectiveness analysis of the current strategy of TTQ used in Spain. Although there is great uncertainty about many parameters of the epidemic, we have obtained an approach robust enough to say that the actual strategy of TTQ is cost-effective and it gets net savings in the long term, i.e. it is dominant. For every euro spent on TTQ, 7 euros will be recovered via saved health-care resources in the base case analysis, which is based on a set of parameter values that proxies the real situation in Spain by the time of the analysis.

In sensitivity analyzes we have altered the parameters for which there is most uncertainty: the positive testing ratio (between $5 \%$ and $15 \%$ ), the number of close contacts of each case (between 1 and 5), the $\%$ with potential for transmission by the time of detection (between $60 \%$ and $90 \%$ ), the adherence rate to isolation (between $60 \%$ and $90 \%$ ), the basic reproductive number R0 (between 0.8 and 1.2), the number of subsequent fortnights of transmissions (i.e. the follow-up horizon, from 1 to 5), the unit cost of PCR testing (between $20 €$ and $60 €$ ) and the percent of hospitalized cases suffering long-term consequences (between 10\% and 40\%). Accounting for the economic costs/ savings of health and morbidity, the TTQ strategy is dominant in every scenario considered.

In the cost-effectiveness calculations, the GDP cost of the epidemy has not been accounted for. The TTQ strategy may contribute to avoid extreme restrictions as strict home lockdowns, which would harm more seriously the economy. By maintaining the R0 below the level that eventually would collapse hospitals and force strict lockdowns, the TTQ strategy could also contribute to alleviating the GDP cost of the epidemic. In our costeffectiveness analysis, we did not include these macroeconomic costs and savings and even 
so we found that for every euro spent on TTQ in Spain, in the base case analysis, seven are recovered, not counting monetized health gains.

The benefit-to-cost ratios we have calculated for Spain are similar to those published for the USA by Atkeson et al. (2020) when only saved health-care resources are considered in our analysis. Furthermore, our results get closer to the values reported in Cutler and Summers (2020) when monetized health gains are included.

In conclusion, the costs of COVID-19 to the global economy are enormous and the estimates presented here place Spain as the European economy most affected by the pandemic. The TTQ strategy conducted in Spain offers a cost-saving measure of spread containment. However, it is worth mentioning that the success of the TTQ strategy strongly depends on its implementation. If there are systematic delays in the detection of cases so that many individuals have already infected other people when diagnosed and isolated, the strategy loses part of its effectiveness. TTQ should, therefore, be well executed, with trained personnel and agility in the times, strictly following the protocols (Rajan et al., 2020).

\section{Notes}

1 Available at: http://ghdx.healthdata.org/gbd-results-tool

2 EuroHealth special issue on Health system responses to COVID-19. Vol 26(2) 2020.

3 www.covid19healthsystem.org/mainpage.aspx

4 Or $397.3 \mathrm{~m} €, 236.9 \mathrm{~m} €$ of them in 2020 and $160.4 \mathrm{~m} €$ in 2121 , considering an exchange of $1.18 €$ per $\$$.

5 www.expansion.com/economia/2020/09/15/5f60d2a5e5fdea87108b4613.html

6 https://momo.isciii.es/public/momo/dashboard/momo_dashboard.html

7 www.mscbs.gob.es/estadEstudios/estadisticas/encuestaNacional/encuesta2011.htm

8 In the week of $9^{\text {th }}$ November, the number of test performed per thousand people in Spain was 3.5. https://ourworldindata.org/coronavirus-testing\#how-many-tests-are-performed-each-day

9 www.isciii.es/QueHacemos/Servicios/VigilanciaSaludPublicaRENAVE/EnfermedadesTransmisibles/ Documents/INFORMES/Informes \% 20COVID-19/Informe \%20COVID-19. \% 20N\%C2\%BA \% 2052_12\%20de \%20noviembre $\% 20$ de $\% 202020$.pdf

10 www.osakidetza.euskadi.eus/contenidos/informacion/osk_servic_para_empresas/es_def/ adjuntos/LIBRO-DE-TARIFAS_2020_osakidetza.pdf

\section{References}

Abásolo Alessón, I., González Lopez-Valcarcel, S. and Rodríguez-Mireles, S. (2020), "La COVID-19 y la sanidad canaria”, Hacienda canaria, Vol. 53, p. 157-178, [ISSN 1696-6945], available at: https:// accedacris.ulpgc.es/jspui/handle/10553/75211

Akobundu, E., Ju, J., Blatt, L. and Mullins, C.D. (2006), "Cost-of-Illness studies”, PharmacoEconomics, Vol. 24 No. 9, pp. 869-890, doi: 10.2165/00019053-200624090-00005.

Aldy, J.E. and Viscusi, W.K. (2007), "Age differences in the value of statistical life: revealed preference evidence", Review of Environmental Economics and Policy, Vol. 1 No. 2, pp. 241-260, doi: 10.1093/reep/rem014.

Alwan, N.A., Burgess, R.A., Ashworth, S., Beale, R., Bhadelia, N., Bogaert, D., Dowd, J., Eckerle, I., Goldman, L.R., Greenhalgh, T., Gurdasani, D., Hamdy, A., Hanage, W.P., Hodcroft, E.B., Hyde, Z., Kellam, P., Kelly-Irving, M., Krammer, F., Lipsitch, M. and Ziauddeen, H. (2020), "Scientific consensus on the COVID-19 pandemic: we need to act now", The Lancet, Vol. 396 No. 10260, pp. e71-e72, doi: 10.1016/S0140-6736(20)32153-X. 
AEA

29,85

88

Atkeson, A., Droste, M., Mina, M.J. and Stock, J.H. (2020), Economic Benefits of COVID-19 Screening Tests, MedRxiv.

Bell, C., Devarajan, S. and Gersbach, H. (2003), The Long-Run Economic Costs of AIDS: Theory and an Application to South Africa, The World Bank, doi: 10.1596/1813-9450-3152.

Bethune, Z.A. (2020), "COVID-19 infection externalities: trading off lives vs. livelihoods [BER working paper 27009”, NBER Working Paapers, National Bureau of Economic Research], Cambridge, MA, available at: https://mic-cimt.ca/now-of-work/bethune-z-a-korinek-a-2020-april-covid-19infection-externalities-trading-off-lives-vs-livelihoods-nber-working-paper-27009-cambridge-manational-bureau-of-economic-research/

Brodeur, A., Gray, D.M., Islam, A. and Bhuiyan, S. (2020), "A literature review of the economics of covid-19 (SSRN scholarly paper ID 3636640). social science research network”, available at: https://papers. ssrn.com/abstract $=3636640$

Byford, S., Torgerson, D.J. and Raftery, J. (2000), “Cost of illness studies”, BMJ, Vol. 320 No. 7245, p. 1335, doi: $10.1136 / \mathrm{bmj} .320 .7245 .1335$.

Carlsson-Szlezak, P., Reeves, M. and Swartz, P. (2020), "What coronavirus could mean for the global economy", Harvard Business Review, Vol. 3.

Cutler, D.M. and Summers, L.H. (2020), "The COVID-19 pandemic and the $\$ 16$ trillion virus", JAMA, Vol. 324 No. 15, pp. 1495, doi: 10.1001/jama.2020.19759.

Cylus, J. and van Ginneken, E. (2020), “covid-19 economic and health financing crisis?”, TEN, Vol. 26 No. 2, p. 25.

Datta, S.D., Talwar, A. and Lee, J.T. (2020), “A proposed framework and timeline of the spectrum of disease due to SARS-CoV-2 infection: illness beyond acute infection and public health implications JAMA", JAMA, Vol. 324 No. 22, doi: 10.1001/jama.2020.22717. Online ahead of print).

Drummond, M.F., Sculpher, M.J., Torrance, G.W., O’Brien, B.J. and Stoddart, G.L. (2005), Methods for the Economic Evaluation of Health Care Programmes, Oxford University Press, Oxford, p. 379 .

Herrera-Araujo, D. and Rochaix, L. (2020), "Does the value per statistical life vary with age or baseline health? Evidence from a compensating wage study in France", Journal of Environmental Economics and Management, Vol. 103, p. 102338, doi: 10.1016/j.jeem.2020.102338.

IMF (2020a), "World economic outlook update, january 2020: tentative stabilization", Sluggish Recovery? IMF, available at: www.imf.org/en/Publications/WEO/Issues/2020/01/20/weo-update-january2020.

IMF (2020b), "Fiscal policies database", IMF, available at: www.imf.org/en/Topics/imf-and-covid19/ Fiscal-Policies-Database-in-Response-to-COVID-19

IMF (2020c), "World economic outlook, october 2020: a long and difficult ascent", IMF, available at: www.imf.org/en/Publications/WEO/Issues/2020/09/30/world-economic-outlook-october-2020

Kulldorff, M., Gupta, S. and Bhattacharya, J. (2020), “Great barrington declaration and petition. Great barrington declaration", available at: https://gbdeclaration.org/

Leal, J., Luengo-Fernández, R., Gray, A., Petersen, S. and Rayner, M. (2006), "Economic burden of cardiovascular diseases in the enlarged european union", European Heart Journal, Vol. 27 No. 13, pp. 1610-1619, doi: 10.1093/eurheartj/ehi733.

Luengo-Fernandez, R., Leal, J., Gray, A. and Sullivan, R. (2013), "Economic burden of cancer across the european union: a population-based cost analysis", The Lancet Oncology, Vol. 14 No. 12, pp. 1165-1174, doi: 10.1016/S1470-2045(13)70442-X.

May, B. (2020), "Coronavirus watch: growers, slowers, and going lowers", available at: https:// resources.oxfordeconomics.com/hubfs/OE-Downloads/0000083.pdf

Ministerio de Sanidad (2020), "INFORMACIÓN CIENTÍFICA-TÉCNICA enfermedad por coronavirus", COVID-19 Actualización, 12 de noviembre 2020, available at: www.mscbs.gob.es/profesionales/ saludPublica/ccayes/alertasActual/nCov/documentos/ITCoronavirus.pdf 
Mo, X., Jian, W., Su, Z., Chen, M., Peng, H., Peng, P., Lei, C., Chen, R., Zhong, N. and Li, S. (2020), "Abnormal pulmonary function in COVID-19 patients at time of hospital discharge", European Respiratory Journal, Vol. 55 No. 6, doi: 10.1183/13993003.01217-2020.

Mulligan, C.B. (2020), "Economic activity and the value of medical innovation during a pandemic (no. w27060)", National Bureau of Economic Research, doi: 10.3386/w27060.

Oliva-Moreno, J., López-Bastida, J., Montejo-González, A.L., Osuna-Guerrero, R. and Duque-González, B. (2009), "The socioeconomic costs of mental illness in Spain", The European Journal of Health Economics, Vol. 10 No. 4, pp. 361-369, doi: 10.1007/s10198-008-0135-0.

Osakidetza (2009), "País vasco: transformando el sistema de salud 2009-2012", available at: www. osakidetza.euskadi.eus/contenidos/informacion/estrategia_cronicidad/es_cronicos/adjuntos/ transformando_sistema_salud.pdf

Osakidetza (2019), "Coste efectivo de los servicios de salud", available at: www.osakidetza.euskadi.eus/ transparencia-buen-gobierno/-/coste-efectivo-servicios-de-salud/

Rajan, S., D. Cylus, J. and Mckee, M. (2020), "What do countries need to do to implement effective 'find, test, trace, isolate and support' systems?", Journal of the Royal Society of Medicine, Vol. 113 No. 7 , pp. 245-250, doi: 10.1177/0141076820939395.

Vallejo-Torres, L., García-Lorenzo, B., Rivero-Arias, O. and Pinto-Prades, J.L. (2020), "The societal monetary value of a QALY associated with EQ-5D-3L health gains", The European Journal of Health Economics, Vol. 21 No. 3, pp. 363-379.

Vallejo-Torres, L., García-Lorenzo, B. and Serrano-Aguilar, P. (2018), "Estimating a cost-effectiveness threshold for the spanish NHS", Health Economics, Vol. 27 No. 4, pp. 746-761, doi: 10.1002/hec.3633.

Vos, T., Lim, S.S., Abbafati, C., Abbas, K.M., Abbasi, M., Abbasifard, M., Abbasi-Kangevari, M., Abbastabar, H., Abd-Allah, F., Abdelalim, A., Abdollahi, M., Abdollahpour, I., Abolhassani, H., Aboyans, V., Abrams, E.M., Abreu, L.G., Abrigo, M.R.M., Abu-Raddad, L.J., Abushouk, A.I., ... Murray, C.J.L. (2020), "Global burden of 369 diseases and injuries in 204 countries and territories, 1990-2019: a systematic analysis for the global burden of disease study 2019", The Lancet, Vol. 396 No. 10258, pp. 1204-1222, doi: 10.1016/S0140-6736(20)30925-9.

Wei, J., Yang, H., Lei, P., Fan, B., Qiu, Y., Zeng, B., Yu, P., Lv, J., Jian, Y. and Wan, C. (2020), “Analysis of thinsection CT in patients with coronavirus disease (COVID-19) after hospital discharge", Journal of XRay Science and Technology, Vol. 28 No. 3, pp. 383-389, doi: 10.3233/XST-200685.

Yu, M., Liu, Y., Xu, D., Zhang, R., Lan, L. and Xu, H. (2020), "Prediction of the development of pulmonary fibrosis using serial Thin-Section CT and clinical features in patients discharged after treatment for COVID-19 pneumonia”, Korean Journal of Radiology, Vol. 21 No. 6, pp. 746-755, doi: 10.3348/kjr.2020.0215.

\section{Corresponding author}

Beatriz González López-Valcárcel can be contacted at: beatriz.lopezvalcarcel@ulpgc.es

For instructions on how to order reprints of this article, please visit our website: 